\title{
Economies of Scale and Efficiency Measurement in Switzerland's Nursing Homes
}

\author{
Mehdi Farsi ${ }^{a}$, Massimo Filippini ${ }^{a, b}$, and Diego Lunati ${ }^{b}$
}

JEL-Classification: C13, C21, D24, H70, I11, I18, L30

Keywords: cost efficiency, economies of scale, nursing homes, stochastic frontier, panel data

\section{Introduction}

Health care costs are steadily growing in all industrialized countries as a result of several supply/demand factors such as the cost-increasing technological progress and the rise in health care prices, the increase in health care demand induced by higher real incomes, and the aging of the population. A low rate of economic growth in conjunction with the increase in public social and health care spending during the last decade induced the Swiss government to restrain the fiscal deficit, contain costs and achieve efficiency gains. Given that a considerable share of the elderly care in the State's health care budget, a special attention could be paid to the possibility of improving the efficiency of the nursing home sector. Moreover, the importance of this sector, with total expenditures approaching two percent of GDP, is expected to grow as the population grows older.

The nursing home industry, with over 1300 providers spread throughout the whole country, represents an important element of the Swiss national system of social welfare and health care. The sector includes various kinds of facilities with different origins and aims. A number of nursing homes have been established at the local level as non-medical centers, whereas others, which serve a higher number of potential users at the district level, are equipped for basic medical services. An important characteristic of the sector is the presence of several

a Department Management, Technology and Economics, ETH Zürich, Zürichbergstrasse 18, 8092 Zurich.

b Department of Economics, University of Lugano, Via Buffi 13, 6904 Lugano. 
institutional forms and various regulation systems. The main ownership categories are private for-profit, non-profit private and public. Thanks to their autonomy in social welfare and health care legislations, Swiss cantons apply different subsidy models to their respective nursing homes. ${ }^{1}$ It is important to point out that in most cantons the state intervenes in both public and private providers by regulating the daily rates, setting quality standards, determining the minimum necessary infrastructure and staff requirements and, above all, by granting a financial contribution in form of subsidies.

With the growing financial pressure on the federal state and cantonal governments, many policy-makers have voiced concerns about the efficiency of the nursing homes. In particular, a dominant perception is that most providers operate at a suboptimal size. The sector has been also criticized for the lack of initiatives to adopt adequate management strategies such as operating multiple-home networks, in order to exploit scale economies. Moreover, it has been argued that as opposed to private firms, heavily subsidized and public facilities do not have strong incentives for saving costs. Much of the ongoing debates remain however qualitative and lack the support of sufficient empirical evidence. The few existing studies in the context of Switzerland are limited to a specific region or lack the data from recent years.

This paper attempts to throw some light on the above policy debates through an econometric analysis of the cost structure of the Swiss nursing homes sector. The presented analysis is based on several stochastic cost frontier models. The paper's focus is on the assessment of the scale economies and the estimation of cost-efficiency. The econometric models have been applied to a national sample of 356 nursing homes operating over the five-year period from 1998 to 2002. Compared to previous research on Swiss nursing homes, this study benefits from a larger data set and an extended set of variables. Moreover, the adopted methodology is based on some of the recent developments in stochastic frontier panel data models, which provide a better account of unobserved heterogeneity across firms.

The remaining part of this paper is organized as follows: A brief review of the relevant literature is provided in section 2 . Section 3 presents the cost model and the specification of the included variables. In section 4 the adopted econometric models are discussed. The data set and the estimation results are described in section 5. Section 6 takes a closer look at the estimates of scale economies and cost efficiency. The conclusions are drawn at the end.

1 Switzerland (7.4 million inhabitants) is a federal State composed of 26 cantons. 


\section{Review of the Literature}

The literature on nursing home industry, focusing on the empirical evaluation of the production and cost structure, is well established and dates back to the $80 \mathrm{~s}$ with the appearance of first econometric studies based on data from the long term care sector. Since then the estimation of a cost function has been performed from many authors with a broad scope of research objectives, but sharing a common problem: the specification of a feasible cost model. In what follows we cite some papers that trace and summarize the evolution in model design and technique choice of the relevant literature for this work: McKay (1988), Vitaliano and Toren (1994), Filippini (2001), Crivelli, Filippini and Lunati (2002) and Farsi, Filippini and KünZle (2005). McKay (1988) estimated a total cost function for a sample of $82 \mathrm{NH}$ operating in Texas in 1983. The cost model is a neoclassical cost function including output (patient days) and input prices (nursing, aide, building \& equipment and services).

Since the main goal of the paper is the measurement of economies of scale in the industry for policy reasons, the problem of quality level is considered by adjusting the model with a quality proxy given by the nursing hours per day ratio. For both models a translog cost function is estimated using the system equation and the ZeLLnER's (1962) seemingly unrelated regression model. The main finding of this study is the presence of scale economies (evaluated at sample mean corresponding to capacity of 70 beds) in the nursing home industry, a result in contrast with the previous studies of that time. Vitaliano and Toren (1994) estimated a stochastic cost frontier for a panel of 164 New York NH in two distinct years (1987 and 1990). The cost model is designed to capture differences in quality, patients turnover and ownership structure.

The estimation technique is based on the composed error term (Aigner, LovelL and SCHMIDT, 1977) which is the core of a stochastic frontier approach. In this paper the focus is on the comparison between the inefficiency levels achieved by different kinds of nursing home and the empirical results show that there's no difference in efficiency over time and among the ownership types. The paper of FilipPini (2001) is the first empirical estimation of a translog cost function on Swiss data. The goal of the paper is the assessment of economies of scale and the data structure utilized is a panel of nursing homes operating in Ticino a Swiss Canton (State) - over the years 1993-1995. The cost model includes two indicators to partially capture the heterogeneity in the output characteristics and in the quality level. The paper suggests the presence of scale economies at the sample median which correspond to a capacity of 60 beds. 
In the paper Crivelli, Filippini and Lunati (2002) the authors extend the empirical analysis to a Swiss sample of 886 nursing home for the year 1998 covering almost all the 26 Cantons (States) of the Swiss Confederation. In order to assess the efficiency level of nursing home industry and the impact of ownership and regulation environment on the cost performance a stochastic cost frontier is estimated. The main findings of the paper are: (1) around the 60\% of the Swiss nursing homes operate close to the national standard for efficiency, achieving scores of $15 \%$ or lower in terms of cost difference to the empirical frontier; (2) there is no statistical evidence of efficiency difference between ownership types and regulatory environment; (3) economies of scale are present and relevant but tend to expire when the capacity reaches 50-60 beds. The work of FARSI, FILIPPINI and KüNZLE (2005) deals with the econometric problem due to unobserved heterogeneity in the stochastic frontier estimation, by applying several methods to the same data set and cost model. The translog cost function is fit to a sample of 36 Swiss nursing homes operating in Ticino over 9 years period (1993-2001). The model includes in the regressors some proxy for quality and patient case-mix (observed heterogeneity) point out that the choice of the econometric approach can influence the empirical results in a substantial way, by considering or not in the efficiency scores the underlying heterogeneity.

\section{Cost Model for Swiss Nursing Homes}

A nursing home can be represented as a production unit transforming two major inputs (capital and labor) into resident-days of long-term care. Such an aggregate measure of output should be complemented with additional variables representing the severity of the case mix of the residents. Moreover, the cost model specification should take into account a number of variables describing output characteristics as well as regional differences, which should capture the heterogeneous dimension of the output of a nursing home. For instance, the costs of operating a nursing home may depend on the type and quality of care provided per resident-day, the level of assistance required by the residents in normal daily activities such as eating, personal care or performing physiological functions and the level of medical assistance required by the residents.

Assuming that output level and input prices are exogenous ${ }^{2}$, and that (for a given technology) firms adjust input factors in order to minimize costs ${ }^{3}$, the

2 These assumptions are the subject of debate in the literature. For an extensive discussion see Breyer (1987).

3 This assumption implies an input orientation for efficiency measurement. 
firm's total operating costs of a nursing home can be represented by the following long run cost function: ${ }^{4}$

$$
T C=f\left(\mathrm{Y}, P_{K}, P_{L}, H, R, D_{f o}, D_{q c}, T\right)
$$

where $T C$ represents the total cost and $Y$ is the output, represented by the total number of resident-days of nursing care.

$P_{k}$ and $P_{l}$ are the prices of capital and labor, respectively. Unfortunately the data which would allow us to calculate the capital stock using the capital inventory method are not available. According to Wagstaffs (1989) and Filippini (2001) the capital stock is approximated by the number of beds owned and operated by a nursing home. The cost of capital is represented by all the expenses apart from labor cost, following the residual capital approach suggested by FriedLAENDER and WANG ChIANG (1983). Hence the capital price is approximated by the capital expenses normalized by the number of available beds in the nursing home. The price of labor is computed as the total labor expenses divided by the total number of full time equivalent employees. Unfortunately the available data do not allow any distinction of labor prices by professional categories.

$H$ is the average assistance time (expressed in hours per day) per resident including both normal daily activities (eating, personal care or performing physiological functions) and medical care. Following McKaY (1988), this variable is introduced in the model to control for differences in the output characteristics. This variable can be interpreted as a proxy for the quality of care as well as a measure of case mix severity through the average required assistance. $R$ is the average medical expenses per patient reimbursed by the health insurance system and is expressed in Swiss Francs. This variable can be considered as a proxy variable for case-mix since there is a negative correlation between the health condition of a resident and the medical expenses reimbursed by the health insurance system.

To better explain total cost differences among Swiss nursing homes, we included a set of dummy variables for different types of nursing homes. The nursing homes that provide part of their care through in-law apartments (less restricted living conditions to residents with a high degree of independence) are distinguished with a dummy variable $\left(D_{f_{0}}\right)$. These are expected to be less costly compared to nursing homes with only rooms located in the main building. The binary indicator $D_{q c}$ represents the high-quality nursing homes with respect to

4 The adopted specification is an extension of that used by Crivelli, Filippini, and Lunati (2002) in a cross-section of Swiss nursing homes. The additional advantage of this study to that paper is the use of panel data. 
care person resident ratio. This dummy is equal to 1 whenever the ratio of the medical and nursing staff to total residents is bigger than 0.424 (median value) implying that for every two residents there is at least one member of the medical staff (either a nurse or a doctor). This variable should distinguish nursing homes operating with different levels of medical and nursing staff and can be viewed as a crude proxy for the quality of care. The model include a linear time trend (T).

The theoretical restrictions related to cost optimization require that the cost function expressed in (1) be concave and linearly homogeneous in input prices and non-decreasing in input prices and output. ${ }^{5}$ The parametric estimation of the cost function (1) requires the specification of a functional form. The translog function offers an appropriate flexible form for answering questions about economies of scale. Being a second-order approximation for any function, translog form does not impose a priori restrictions on the nature of technology. In particular, the values for economies of scale can vary with output. The linear homogeneity restriction is imposed by setting the price of capital as the numeraire. The complete cost frontier model function results as:

$$
\begin{aligned}
\ln \left(T C / P_{K}\right)=\alpha_{0} & +\alpha_{y} \ln y+\alpha_{L} \ln \left(P_{L} / P_{K}\right) \\
& +\alpha_{H} \ln H+\alpha_{R} \ln R \\
& +\alpha_{y y} 0.5 \ln ^{2} y+\alpha_{L L} 0.5 \ln ^{2}\left(P_{L} / P_{K}\right) \\
& +\alpha_{H H} 0.5 \ln ^{2} H+\alpha_{R R} 0.5 \ln ^{2} R \\
& +\alpha_{y L} \ln y \ln \left(P_{L} / P_{K}\right) \\
& +\alpha_{y H} \ln y \ln H+\alpha_{y R} \ln y \ln R \\
& +\alpha_{L H} \ln \left(P_{L} / P_{K}\right) \ln H \\
& +\alpha_{L R} \ln \left(P_{L} / P_{K}\right) \ln R+\alpha_{H R} \ln H \ln R \\
& +\alpha_{f o} D_{f o}+\alpha_{q c} D_{q c}+\alpha_{T} T+\alpha_{i}+\varepsilon_{i t}
\end{aligned}
$$

Considering the sample median as the approximation point, all the variables have been normalized to their respective sample median values. Subscripts $i$ and $t$ respectively denote the nursing home and year, $\alpha_{i}$ is a firm-specific effect and $\varepsilon_{i t}$ is an iid error term. As we will explain in the next section, in the recent models proposed by GREENE (2005), the stochastic term $\varepsilon_{i t}$ is decomposed into two parts: a skewed component representing inefficiency and a symmetric part for the random noise.

5 See Cornes (1992), p. 106. 


\section{Methodology}

Cost frontier analysis can be used to estimate indicators of cost-efficiency and scale economies. The use of cost frontier models to evaluate efficiency in the health-care sector has been criticized by Newhouse (1994) and Skinner (1994). The main arguments against these models are related to the unobserved heterogeneity due to differences in case-mix and quality and the errors committed by aggregation of outputs as well as non-testable assumptions on the distribution of efficiency. Folland and Hofler (2001) provide a discussion on the reliability of hospital efficiency estimates obtained from stochastic cost frontier models. These authors show that the individual efficiency estimates are rather sensitive to the adopted model specification and functional form. However, the results are robust when the comparisons are performed between hospital group mean inefficiencies. This finding is consistent with the results reported by HADLEY AND ZUCKERMAN (1994) suggesting that the stochastic frontier analysis is of practical use when applied for comparing group means of hospital efficiency. Crivelli, Filippini and Lunati (2002), FARsi, Filippini and KünZle (2005) and Farsi and FilipPini (2008) reached a similar conclusion in their studies regarding nursing homes and general hospitals. Although nursing homes have generally a more uniform case-mix than hospitals, the above arguments apply more or less to these providers as well.

There are several parametric cost frontier methods to estimate the cost efficiency of individual firms. Kumbhakar and Lovell (2000) provide an intensive survey of various models proposed in the literature. The main models used in this paper are based on GREENE's (2005) extension for panel data of the original frontier approach proposed by Aigner, Lovell and Schmidt (1977). In this framework, $\varepsilon_{i t}$ in equation (2) is assumed to be a composite stochastic term with a normal-half-normal distribution, including both idiosyncratic effects and inefficiencies. The additional firm-specific term, $\alpha_{i}$ in equation (2), represents the unobserved heterogeneity and is assumed to have a normal distribution. This model is referred to as the "true" random-effects model. ${ }^{6}$ The estimation method is based on simulated maximum likelihood.

The results are compared with two alternative models namely, the randomeffects model proposed by SCHMIDT and SickLES (1984) and the original pooled model proposed Aigner, Lovell and Schmidt (1977). A summary of the three models used in the paper is given in Table 1.

6 The name "true" is chosen to show that the model keeps the original frontier framework and the extension is done only by including an additional heterogeneity term. 
Table 1: Econometric Specifications of the Stochastic Cost Frontier

\begin{tabular}{lccc}
\hline & $\begin{array}{c}\text { Model I } \\
\text { Pooled }\end{array}$ & $\begin{array}{c}\text { Model II } \\
\text { RE-GLS }\end{array}$ & $\begin{array}{c}\text { Model III } \\
\text { True RE }\end{array}$ \\
\hline Firm-specific component $\alpha_{\mathrm{i}}$ & None & iid $\left(0, \sigma_{\alpha}{ }^{2}\right)$ & $\mathrm{N}\left(0, \sigma_{\alpha}{ }^{2}\right)$ \\
Random error $\varepsilon_{i t}$ & $\begin{array}{c}\varepsilon_{i t}=u_{i t}+v_{i t} \\
u_{i t} \sim \mathrm{N}^{+}\left(0, \sigma_{u}{ }^{2}\right)\end{array}$ & iid $\left(0, \sigma_{\varepsilon}{ }^{2}\right)$ & $\begin{array}{c}\varepsilon_{i t}=u_{i t}+v_{i t} \\
v_{i t} \sim \mathrm{N}\left(0, \sigma_{v}{ }^{2}\right)\end{array}$ \\
& $\mathrm{E}\left[u_{i t} \mid u_{i t}+v_{i t}\right]$ & $\mathrm{E}\left[\alpha_{i} \mid \omega_{i 1}, \omega_{i 2}, \ldots\right]$ & $\begin{array}{c}\mathrm{N}_{i t}\left(0, \sigma_{u}{ }^{2}\right) \\
v_{i t} \sim \mathrm{N}\left(0, \sigma_{v}{ }^{2}\right)\end{array}$ \\
& & $\mathrm{E}\left[u_{i t} \mid \alpha_{i t}+\varepsilon_{i t}\right]$ \\
Inefficiency $\omega_{i t}=\alpha_{i}+\varepsilon_{i t}$ & \\
\hline
\end{tabular}

The first model is a pooled frontier model in that the sample is considered as a cross-section and its panel aspect is neglected. In this model there is no firmspecific component $\alpha_{i}$ and the random error term is divided into two components: a normal error term $v_{i t}$ capturing the noise and a half-normal random term $u_{i t}$ representing the inefficiency as a one-sided non-negative disturbance. This model is based on the original cost frontier model proposed by Aigner, LovelL and Schmidt (1977). The firm's inefficiency is estimated using the conditional mean of the inefficiency term $\mathrm{E}\left[u_{i t} \mid u_{i t}+v_{i t}\right]$, proposed by Jondrow, LovelL, Materov and Schmidt (1982).

Model $I I$ is a random effects (RE) model that is estimated using GLS method. In this model the inefficiency scores are estimated as the distance from the firm with the minimum estimated random effect, that is $\hat{a}_{i}-\min \left\{\hat{a}_{i}\right\}$, as proposed by Schmidt and Sickles (1984). In this model the firm's inefficiency is assumed to be constant over time, thus captured by the firm-specific effects, while in other models inefficiency can vary across years. The RE model assumes that all the cost variation across firms that cannot be explained by the included explanatory variables, are due to efficiency differences. This assumption is rather restrictive in the health sector, where the services are generally characterized by strong heterogeneity across the users. Especially in the case of long-term care, many of these characteristics could be time-invariant over the relatively short periods covered in the usual samples, thus could bias the efficiency estimates.

Model $I I I$ is an extension to model $I$ which includes an additional firm-specific random effect $\left(\alpha_{i}\right)$ to represent the unobserved heterogeneity among firms. Model III is Greene's (2005) true RE model. In this model it is assumed that the unobserved cost differences across firms that remain constant over time, are driven by firm-specific unobserved characteristics rather than inefficiency. In the context of nursing homes, the unobserved factors such as differences in quality and case- 
mix severity across providers could be very important. Therefore, it is crucial to disentangle such differences from inefficiency. However, the distinction between the two requires certain non-testable assumptions. The true RE model assumes that persistent cost differences are related to unobserved heterogeneity across firms rather than efficiency differences. On the other hand, the inefficiency term is assumed to be an iid random variable with half-normal distribution. This implies that inefficiencies are not persistent and each period brings about new idiosyncratic elements thus new sources of inefficiency. This is a reasonable assumption particularly in industries that are constantly facing new technologies or time-variant external factors such as changing labor prices and regulation constraints.

In the RE model $I I$, the inefficiencies are assumed to be constant over time. This could be an unrealistic assumption in most practical cases, where the driving forces of cost-inefficiency are not generally persistent. In fact firms constantly face new problems emerging from the implementation of new techniques, or from dealing with new regulation systems, or other external constraints. Moreover, there exist incentive mechanisms (either through regulation and monitoring or through profit and career incentives) that induce managers to revise their strategies and correct their past suboptimal decisions. To what extent this is the case in the context of nursing home sector in Switzerland, is open to debate. However, the presence of time-invariant unobserved output characteristics that are specific to location and case-mix but beyond the management's control is undeniable.

Another important issue is that in all the above models it is assumed that the unobserved firm-specific output characteristics are uncorrelated with the explanatory variables. This assumption might be restrictive and its violation could bias the coefficients of the cost function, hence distort the estimates of scale economies. The effect of such biases on the efficiency estimates depends on whether or not the "true" inefficiencies are correlated with unobserved heterogeneity or the included explanatory variables. If inefficiencies are not allowed to have such a correlation, then the bias on coefficients does not affect the efficiency estimates. Since the true values of efficiency are not known, the assumption of no correlation between efficiency and other factors is not testable. We contend however that such an assumption is consistent with the original spirit of the frontier models in which the inefficiency is defined as cost-differences that cannot be explained by other factors.

As for the potential bias in the cost function's slopes, fixed effects models based on within estimators can be helpful. However, given that our data is a rather short panel of 5 years, ${ }^{7}$ the statistical efficiency of fixed effects models depends on the

7 See Greene $(2002,2005)$ for more details. This author considers a panel of 5 years as a short panel. In contrast with "between" variations that are related to the differences across 
level of variation of costs and explanatory variables especially output, within firms. Our preliminary analysis with several fixed effects specification indicates high estimation errors and lack of statistical significance for many of the important explanatory variables. This can be explained by the fact that in the main variables, the within variations are comparatively insignificant compared to the dominating between variations. Moreover, the inefficiency estimates from the fixed effects models are implausibly high (reaching easily to $100 \%$ of costs), suggesting that they capture some of the between variations that are not related to inefficiency. ${ }^{8}$ Therefore, we decided to exclude the fixed effects model.

\section{Data and Estimation Results}

The data used for this study have been provided by the Swiss Federal Statistical Office. The original sample consisted of 3474 observations from 1070 nursing homes operating from 1998 to 2002. By nursing homes, we mean the facilities that provide full-time long-term care as well as basic medical care to the elderly people. After excluding the observations with missing values and the invalid data, the final sample includes 1780 observations from 356 nursing homes resulting in a balanced panel of 5 years. ${ }^{10}$ The sample includes of 73 public, 218 private non profit and 65 private for profit nursing homes.

Excepting the quality measures the data set was sufficiently detailed to ensure an adequate specification of the cost model. All the financial data have been deflated according to the Swiss consumer price index based on May 2000 prices. In Table 2 we present the main descriptive statistics for the continuous variables included in the regression.

companies, "within" variations correspond to the changes in a given company over time. Roughly speaking, even a long panel data with low within variation is equivalent, for econometric purposes, to a short panel data.

8 See Farsi, Filippini and KünZle (2005) for more details on the problems of fixed effects models in estimating efficiency.

9 The Swiss nursing home industry is composed by several heterogeneous facilities. In this study we used the definition of nursing home proposed by the Federal Statistical Office. Moreover, in order to keep a relatively homogeneous sample we excluded facilities that do not provide any medical care, identified by zero reimbursement from health insurance systems.

10 We exclude all the observations with evidently unrealistic values such as extreme outliers. In addition, we excluded nursing homes with less than 10 beds and also those with a bed occupancy rate of less than $10 \%$. 
Table 2: Descriptive Statistics for Cost Model Variables

\begin{tabular}{llccccc}
\hline Variable (Label) & unit & Mean & St. Dev. & $1^{\text {st }}$ qu.le & Median & $3^{\text {rd }}$ qu.le \\
\hline Total cost (TC) & CHF & $4,563,181$ & $3,646,319$ & $2,087,600$ & $3,606,600$ & $6,070,200$ \\
Output $(\mathrm{Y})$ & Patient-days & 22,501 & 15,806 & 11,960 & 18,802 & 27,968 \\
Labor price $\left(\mathrm{P}_{\mathrm{L}}\right)$ & CHF/worker & 69,765 & 13,371 & 62,228 & 69,375 & 76,867 \\
Capital price $\left(\mathrm{P}_{\mathrm{K}}\right)$ & CHF/bed & 21,325 & 10,401 & 13,967 & 18,491 & 25,485 \\
Care giving $(\mathrm{H})$ & care hours/resident & 2.793 & 1.118 & 1.950 & 2.646 & 3.617 \\
Reimbursement $(\mathrm{R})$ & CHF/resident & 20,540 & 12,011 & 12,219 & 18,011 & 25,822 \\
Average Cost & CHF/resident-day & 201.8 & 62.6 & 155.3 & 191.9 & 239.7 \\
Number of nursing home beds & 64.2 & 45.4 & 35 & 53 & 81 \\
\hline
\end{tabular}

The results of the estimates for the total cost frontier function (3) under different econometric specifications are presented in Table 3. Most of the first and second order terms are statistically significant in all the specifications. Since total costs and all the regressors are in logarithms, the first order coefficients can be interpreted as cost elasticities evaluated at the approximation point that is the sample median. All these coefficients have the expected signs and are highly significant.

The output elasticity is positive and implies that an increase in supply will raise the total cost. The increase in total cost, as a response to a $10 \%$ increase in the number of patient-days, corresponds to $9.8 \%$ for the pooled model and is just slightly smaller (9.4\%) for the other two models. These results, showing some variability in the parameter estimates, are fairly similar across different econometric specifications. ${ }^{11}$ This suggests that the heterogeneity biases due to potential correlation between explanatory variables and firm-specific unobserved factors are not of a considerable order.

The labor and capital cost shares are positive, implying that the cost function is monotonically increasing in input prices. The cost elasticities with respect to the output characteristics ( $H$ and $R)$ are, as expected, positive. This result suggests that a ceteris paribus increase in the average assistance time and in the reimbursement per patient will lead to an increase in total cost.

11 In the estimation process we also evaluate several alternative specifications for each of the three presented models. The estimation results were quite stable across the three econometric specifications. 
Table 3: Estimation Results

\begin{tabular}{|c|c|c|c|c|c|c|}
\hline \multirow[b]{2}{*}{$\alpha_{\mathrm{y}}$} & \multicolumn{2}{|c|}{$\begin{array}{l}\text { Model I } \\
\text { Pooled }\end{array}$} & \multicolumn{2}{|c|}{$\begin{array}{l}\text { Model II } \\
\text { RE-GLS }\end{array}$} & \multicolumn{2}{|c|}{$\begin{array}{l}\text { Model III } \\
\text { True RE }\end{array}$} \\
\hline & 0.985 & $(0.005)$ & 0.935 & $(0.010)$ & 0.939 & $(0.010)$ \\
\hline$\alpha_{\mathrm{L}}$ & 0.640 & $(0.008)$ & 0.591 & (0.009) & 0.576 & $(0.007)$ \\
\hline$\alpha_{\mathrm{H}}$ & 0.101 & $(0.009)$ & 0.052 & (0.009) & 0.044 & (0.009) \\
\hline$\alpha_{\mathrm{R}}$ & 0.069 & $(0.007)$ & 0.038 & $(0.007)$ & 0.029 & $(0.006)$ \\
\hline$\alpha_{\mathrm{yy}}$ & 0.036 & $(0.011)$ & 0.238 & $(0.017)$ & 0.196 & (0.013) \\
\hline$\alpha_{\mathrm{LL}}$ & 0.068 & $(0.025)$ & 0.052 & $(0.020)$ & 0.042 & $(0.014)$ \\
\hline$\alpha_{\mathrm{HH}}$ & 0.113 & $(0.036)$ & 0.097 & $(0.026)$ & 0.068 & $(0.021)$ \\
\hline$\alpha_{\mathrm{RR}}$ & 0.044 & $(0.017)$ & 0.063 & $(0.013)$ & 0.042 & $(0.012)$ \\
\hline$\alpha_{\mathrm{yL}}$ & 0.033 & $(0.012)$ & 0.035 & $(0.012)$ & 0.027 & (0.009) \\
\hline$\alpha_{\mathrm{yH}}$ & -0.004 & $(0.012)$ & -0.035 & $(0.012)$ & -0.036 & (0.009) \\
\hline$\alpha_{\mathrm{yR}}$ & 0.055 & $(0.009)$ & 0.084 & (0.009) & 0.065 & $(0.006)$ \\
\hline$\alpha_{\mathrm{LH}}$ & 0.102 & $(0.019)$ & 0.044 & $(0.015)$ & 0.048 & $(0.012)$ \\
\hline$\alpha_{\mathrm{LR}}$ & 0.019 & $(0.017)$ & 0.034 & $(0.013)$ & 0.035 & $(0.010)$ \\
\hline$\alpha_{\mathrm{HR}}$ & -0.126 & $(0.019)$ & -0.119 & $(0.014)$ & -0.102 & $(0.011)$ \\
\hline$\alpha_{\mathrm{fo}}$ & -0.055 & $(0.013)$ & -0.072 & $(0.013)$ & -0.066 & $(0.010)$ \\
\hline$\alpha_{\mathrm{qc}}$ & 0.174 & $(0.008)$ & 0.077 & $(0.006)$ & 0.071 & $(0.007)$ \\
\hline$\alpha_{\mathrm{T}}$ & 0.007 & $(0.002)$ & 0.014 & $(0.001)$ & 0.015 & $(0.001)$ \\
\hline$\alpha_{\overline{0}}$ & 14.894 & $(0.009)$ & 14.961 & (0.009) & 14.887 & (0.009) \\
\hline$\sigma_{\alpha}$ & - & - & - & - & 0.153 & $(0.006)$ \\
\hline$\sigma$ & 0.178 & $(0.0008)$ & - & - & 0.110 & $(0.002)$ \\
\hline$\lambda=\sigma_{\mu} / \sigma_{v}$ & 1.251 & $(0.066)$ & - & - & 2.137 & $(0.173)$ \\
\hline
\end{tabular}

All the coefficients except those in shaded fields are statistically significant at $1 \%$ significance level. Standard errors are given in brackets.

The dummy variable $D_{f_{0}}$ that distinguishes nursing homes with in-law apartments is negative and statistically significant. This result can be explained by the fact that generally in the residents of these apartments require a lower degree of assistance compared to those living in ordinary nursing home. The dummy variable $D_{q c}$ introduced to explain the quality of provided care, is positive and suggests that a higher ratio of medical staff per patient raises costs. Finally the time trend $(\mathrm{T})$ is positive indicating an upward cost shift over time. 


\section{Economies of Scale and Cost Efficiency}

In this section we turn to a detailed analysis of estimation results regarding scale and cost efficiency. The analysis of scale economies is aimed at identifying if and to what extent the nursing homes exploit the potential cost reductions related to higher output levels. The concept of economies of scale indicates the degree to which a company operates at the optimal scale. FrISCH (1965) defines the optimal scale as the level of operation where the average costs are minimum, which coincides with a unit value for the scale elasticity. Hence, the economies of scale (ES) are defined as the inverse of scale elasticity, which is the proportional increase in total costs resulting from a proportional increase in the output $(Y)$, holding all input prices and other explanatory variables fixed:

$$
E S=(\partial \ln T C / \partial \ln Y)^{-1}
$$

There are unexploited economies of scale if $E S$ is greater than 1 and, conversely, there are diseconomies of scale if $E S$ is lower than 1. In other words economies (diseconomies) of scale exist if the average cost of a nursing home decreases (increases) as output increases.

Table 4 presents in more details the results in term of economies of scale for the different specifications. The output levels (total resident-days over a year) have been transformed to an equivalent number of beds assuming a full occupancy rate. The value of ES for the small (33 beds) and medium ( 51 beds) sized nursing homes is greater than 1 for all specifications and this means that economies of scale still exist at the sample median. In other words, half of the units observed in the sample could reduce total costs by increasing their output.

Table 4: Economies of Scale

\begin{tabular}{lcccc}
\hline Economies of Scale & $\begin{array}{c}\mathrm{Y}=1^{\text {st }} \\
\text { (Size }=33 \text { beds })\end{array}$ & $\begin{array}{c}\mathrm{Y}=\text { median } \\
(\text { Size }=51 \text { beds })\end{array}$ & $\begin{array}{c}\mathrm{Y}=3^{\text {rd }} \text { Quartile } \\
(\text { Size }=77 \text { beds })\end{array}$ & $\begin{array}{c}\text { Optimal size } \\
(\mathrm{ES}=1)\end{array}$ \\
\hline Model I: Pooled & 1,038 & 1,015 & 1,007 & 93 beds \\
Model II: RE-GLS & 1,267 & 1,069 & 1,008 & 79 beds \\
Model III: True RE & 1,221 & 1,065 & 1,014 & 82 beds \\
\hline
\end{tabular}

Note: Number of beds is computed as the output in patient-days (Y) divided by 365 days. 
The optimal size $(E S=1)$ for a nursing home corresponds to the minimum of the estimated average cost frontier which depends on the days of care offered $(\mathrm{Y})$ but also on other regressors. The optimal size figures correspond to the minimum of the average cost frontier.

The cost minimizing size is given by an extension of output $(\mathrm{Y})$ keeping all the other variables of the model constant to their respective median values. The number of beds corresponding to the optimal size varies according to the different econometric specifications (table 3) but we can safely consider the bed interval 75-95 as a reliable indication for the optimal size of a representative nursing home. This optimal level can be compared to the actual distribution of the nursing homes capacity presented in Figure 1. This distribution is characterized by a strong concentration around the median value of 53 beds. ${ }^{12}$

Figure 1. Box-Plot of the Actual Size (Number of Beds) Based on the Estimation Sample

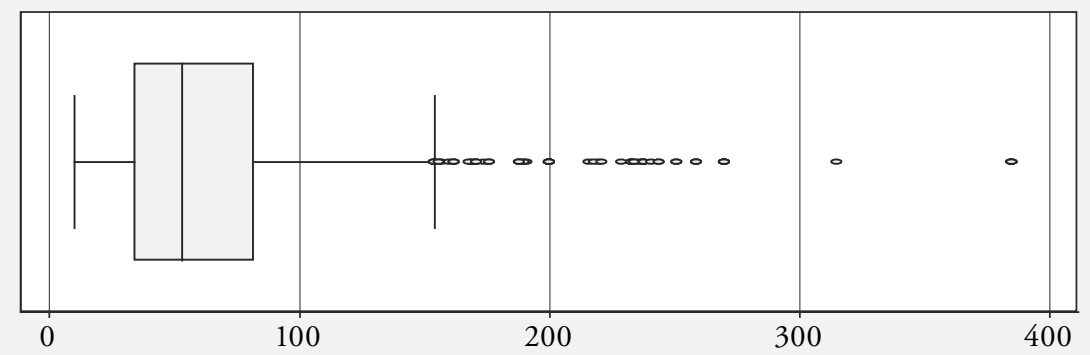

The estimation results (see Table 4) show that in the Swiss nursing home industry most of the firms are operating at a sub-optimal size. This widespread scale inefficiency could be justified with two arguments: quality and access. The quality argument relies on the fact that often a nursing home's priority is to maintain a comfortable and friendly living environment, which is more easily achieved in a small institution. The access argument is based on the importance of providing a social service to elderly people also in rural and border area. In the Swiss case, another explanation for the small dimensions of many nursing homes could be fiscal federalism. In the past municipalities were responsible for providing care of

12 The high concentration around the median value as shown in Figure 1 suggests that the sample median can be considered as an appropriate representative nursing home for the sector. 
their elderly populations and, of course, this situation produced a huge numbers of small nursing homes throughout the country. It should be noted that because of capacity constraints, an existing small nursing home cannot simply increase its output to exploit the scale economies. We contend that such nursing homes could however exploit certain economies of scale through cooperation with neighboring nursing homes in different areas such as sharing their staff, joint purchase of drugs and materials, laundry and other services.

The results reported in Table 4 are confirmed by the results obtained in previous studies using data on Swiss nursing homes. Table 5 illustrates the results obtained in these studies. The study by FiLIPPINI (2001) and FARSI and FiLIPPINI (2004) estimate a cost function using panel data for a sample of nursing homes operating in Canton Ticino. Crivelli, Filippini and Lunati (2002) estimate a cost frontier model using a cross-section for a sample of Swiss nursing homes. The values of the optimal size reported in the studies by FARsI and FILIPPINI (2004) and Filippini (2001) are higher than those reported in this study and in the study by Crivelli, Filippini and Lunati (2002). This difference may be due to the different data set and to the different econometric approaches used. For instance, Farsi and Filippini (2004) were able to use a rich panel data set composed of 36 nursing homes operating in Ticino over the 9-year period from 1993 to 2001.

Table 5: Previous Results Regarding Scale Economies in Swiss Nursing Homes

\begin{tabular}{|l|c|c|c|}
\cline { 2 - 4 } \multicolumn{1}{c|}{} & $\begin{array}{c}\text { Crivelli, Filippini } \\
\text { and Lunati (2002) }\end{array}$ & $\begin{array}{c}\text { Farsi and Filippini } \\
(2004)\end{array}$ & $\begin{array}{c}\text { Filippini } \\
(2001)\end{array}$ \\
& $\begin{array}{c}\text { Frontier } \\
\text { All Switzerland } \\
\text { Cross section (1998) } \\
\text { MLE (Aigner) }\end{array}$ & $\begin{array}{c}\text { Frontier } \\
\text { Ticino } \\
\text { PANEL (1993-01) } \\
\text { REM (PitT-LeE) }\end{array}$ & $\begin{array}{c}\text { SUR } \\
\text { Ticino } \\
(1993-1995)\end{array}$ \\
\hline Optimal size at median & 79 beds & 120 beds & 120 beds \\
\hline
\end{tabular}

Table 6 shows summary statistics of inefficiency scores, calculated for the nursing homes included in the sample. The value of inefficiency can be read as a percentage of cost beyond the frontier value obtained by a fully efficient unit. For instance, a score of 0.24 indicates that the actual cost of a nursing home is $24 \%$ higher than the (estimated best practice) fully efficient level. The inefficiency scores are relatively sensitive to different model specifications. 
Table 6: Inefficiency Scores Descriptive Statistics

\begin{tabular}{lccc}
\hline Inefficiency & Model I Pooled & Model II RE-GLS & Model III True RE \\
\hline Mean & 0.117 & 0.621 & 0.081 \\
Median & 0.105 & 0.616 & 0.067 \\
Maximum & 0.670 & 1.400 & 1.184 \\
90 percentile & 0.184 & 0.942 & 0.135 \\
Minimum & 0.021 & 0 & 0.012 \\
\hline
\end{tabular}

As discussed earlier, assuming that the unobserved firm-specific factors are not correlated with efficiency differences the estimates obtained from the true RE are pure inefficiency separated from unobserved heterogeneity. Nonetheless this model cannot detect the presence of time-invariant inefficiency, which is captured by the firm-specific term, leading to a (possible) downward bias in efficiency estimates. On the other hand, the RE-GLS model considers any time-invariant variation in the model's residuals as inefficiency. This model is therefore likely to create an upward bias in the inefficiency scores. Finally, the pooled model does not assume any distinction between time-variant and time-invariant residuals. The separation of inefficiency and heterogeneity is based on a simple distribution assumption considering the symmetric residual component as heterogeneity and the skewed part as inefficiency.

Looking at Table 6, and noting the above discussion, it is clear that identifying the inefficiency level in the sector is rather contentious. Due to the importance of unobserved factors related to quality of care we contend that the true RE model's estimates are on the safe side. According to this model, the median inefficiency score is 0.067 suggesting that about $50 \%$ of the nursing homes in the sample are operating with a total cost that is $6,7 \%$ higher than the minimum possible cost, and in 90 percent of the cases, the inefficiency is limited to $13,5 \%$. This result shows that the majority of Swiss nursing homes are operating relatively close to the fully efficient cost frontier.

Regarding the efficiency differences across nursing homes with different ownership types, we applied several statistical tests on the inefficiency scores estimated from the three models. We used a non-parametric rank test (KRUSKALWALlis, 1952) as well as t-tests across three groups of nursing homes: public, private non-profit (NP) and private for profit (FP). The estimation results suggest that on average the public nursing homes are the least efficient group followed by NP providers and that the FP nursing homes are on average the most 
cost-efficient category. This result is confirmed across all three econometric specifications. However, the practical and statistical significance of the differences varies across the models. The true RE model does not provide any evidence of significant differences. The null hypothesis of no difference cannot be rejected at any significance level. On the other hand the pooled and RE-GLS models favor the statistical significance of efficiency differences. However, it should be noted that the practical significance of these differences is questionable. According to the pooled model the average efficiency differences across the ownership categories is always below $1 \%$. In the case of RE model the predicted efficiency differences can go up to $7-8$ percent with the maximum difference between public and FP categories.

\section{Conclusions}

The purpose of this study was to analyze the cost structure of a sample of Swiss nursing homes in order to assess economies of scale and cost inefficiency. Policymakers are particularly interested in cost information in order to determine the optimal size of a nursing home. Moreover, this paper measures cost efficiency under different econometric specifications. Four different stochastic frontier cost models have been considered. A translog cost function was estimated using an unbalanced panel of 356 nursing homes operating in Switzerland from 1998 to 2002. The main conclusions of this study with respect to the adopted methodology and the empirical implications can be shortly summarized.

Empirical evidence indicates that economies of scale are exhausted up to a capacity of beds ranging from 75 to 95 beds. This result suggests that the effects of size on costs should be taken into account in building new nursing homes. This result also points to the economic advantages of joint activities between small nursing homes, and eventually consolidation of small facilities through mergers and acquisitions. The outcome of this analysis, according to the most favorable results, shows that over $75 \%$ of the nursing homes included in our sample operate close (not more than 10\%) to the national (relative) best practice for efficiency. The average inefficiency is about $7 \%$ of cost excess above the (estimated) Swiss best-practice. The results also point to possible efficiency differences across different types of ownership. However, depending on the adopted econometric model and the assumptions related to unobserved factors, these differences are either statistically insignificant or mostly of no practical significance.

We would like to stress that with the available short panel, the unobserved heterogeneity at the firm level cannot be sufficiently considered and the empirical 
results especially concerning the individual efficiency estimates should be considered with caution. Secondly, we note that the two purposes of our estimations require somewhat different conditions in the model. As we have seen earlier the pooled model ignores the panel structure of the data, thus may result in biased estimates of the slopes, whereas, the panel data models control to some extent, for the unobserved heterogeneity, thus should have a lower bias in the slope estimates. Therefore, the estimated scale economies from the panel model are more reliable, or at least they can indicate the direction of such biases. Finally, there are potentially important quality differences across different ownership categories, which have not been accounted in this analysis and requires further research and more elaborate data. These points should be kept in mind in the interpretation and application of the results presented in this paper for policy purposes.

\section{References}

Aigner, D. J., Lovell, C. A. K., and Schmidt, P. (1977), "Formulation and Estimations of Stochastic Frontier Production Function Models", Journal of Econometrics 6, pp. 21-37.

Battese, G. E., and Coelli, T. J. (1992), "Frontier Production Functions, Technical Efficiency and Panel Data: With Application to Paddy Farmers in India", Journal of Productivity Analysis, 3 (1), pp. 153-169.

Breyer, F. (1987), "The Specification of a Hospital Cost Function." The Review of Economics and Statistics, 79(3), pp. 443-453.

Coelli, T., Estache, A., Perelman, S., and Trujillo, L. (2003), A Primer on Efficiency Measurement for Utilities and Transport Regulators, World Bank Institute Development studies, The World Bank, Washington DC.

Coelli, T., Rao, D. S. P., and Battese, G. E. (1998), An Introduction to Efficiency and Productivity Analysis, Boston.

Cornes, R. (1992), Duality and Modern Economics, New York.

Cornwell, C., Schmidt, P., and Sickles, R. C. (1990), "Production Frontiers with Cross-Sectional and Time-Series Variation in Efficiency Levels", Journal of Econometrics, 46 (1990), pp. 185-200.

Crivelli, L., Filippini, M., and Lunati, D. (2002), "Regulation, Ownership and Efficiency in the Swiss Nursing Home Industry", International Journal of Health Care Finance and Economics, 2 (2), pp. 79-97.

Farsi, M., and Filippini, M. (2008), "Effects of Subsidization and Teaching Activities on Hospital Costs in Switzerland”, Health Economics, 17 (3), pp. 335-350. 
Farsi, M., and Filippini, M. (2004), "An Empirical Analysis of Cost Efficiency in Non-profit and Public Nursing Homes", Annals of Public and Cooperative Economics, 75 (3), pp. 339-365.

Farsi, M., Filippini, M., and Künzle, M. (2005), "Unobserved Heterogeneity in Stochastic Cost Frontier Models: An Application to Swiss Nursing Homes", Applied Economics, 37, pp. 2127-2141.

Filippini, M. (2001), "Economies of Scale in the Swiss Nursing Home Industry", Applied Economics Letters 8, pp. 43-46.

Folland, S. T., and Hofler, R. A. (2001), "How Reliable are Hospital Efficiency Estimates? Exploiting the Dual to Homothetic Production", Health Economics, 10, pp.683-698.

Friedlaender, A. F., and Wang Chiang, S. J. (1983), "Productivity Growth in the Regulated Trucking Industry", Research in Transportation and Economics 1, pp. 149-184.

Frisch, R. (1965), Theory of Production, Chicago.

Greene, W. (2005), "Reconsidering Heterogeneity in Panel Data Estimators of the Stochastic Frontier Model”, Journal of Econometrics, 126 (2), pp. 269-303.

Greene, W. (2002), "Alternative Panel Data Estimators for Stochastic Frontier Models", Working paper, Stern School of Business, New York University (September 2002).

Hadley, J., and Zuckerman, S. (1994), "The Role of Efficiency Measurement in Hospital Rate Setting", Journal of Health Economics, 13, pp.335-340.

Jondrow, J., Lovell, C. A. K., Materov, I. S., and Schmidt, P. (1982), “On Estimation of Technical Inefficiency in the Stochastic Frontier Production Function Model", Journal of Econometrics, 19, pp. 233-238.

Kruskal, W. H., and Wallis, W. A. (1952), "Use of Ranks in One-Criterion Variance Analysis", Journal of the American Statistical Association, 47 (260), pp. 583-621.

Kumbhakar, S. C., and Lovell, C. A. K. (2000), Stochastic Frontier Analysis, New York.

McKay, N. L. (1988), "An Econometric Analysis of Cost and Scale Economies in the Nursing Homes Industry", Journal of Human Resources 23, pp. 57-75.

Newhouse, J. P. (1994), "Frontier Estimation: How Useful a Tool for Health Economics", Journal of Health Economics, 13, pp. 317-322.

Pitt, M., and LeE, L. (1981), "The Measurement and Sources of Technical Inefficiency in Indonesian Weaving Industry", Journal of Development Economics, 9, pp. 43-64.

Schmidt, P., and Sickles, R. C. (1984), "Production Frontiers and Panel Data", Journal of Business and Economic Statistics, 2, pp. 367-374. 
Simar, L. (1992), "Estimating Efficiencies from Frontier Models with Panel Data: A Comparison of Parametric, Non-parametric and Semi-parametric Methods with Bootstrapping", The Journal of Productivity Analysis, 3, pp. 171-203.

Simar, L., and Wilson, P. W. (2000), "Statistical Inference in Nonparametric Frontier Models: The State of the Art", Journal of Productivity Analysis, 13, pp. 49-78.

Singh, S., and Coelli, T. (2001), "Performance of Dairy Plants in the Cooperative and Private Sectors in India", Annals of Public and Cooperative Economics, 72 (4), pp. 453-479.

Skinner, J. (1994), "What Do Stochastic Frontier Cost Functions Tell Us about Inefficiency?", Journal of Health Economics, 13, pp.323-328.

Vitaliano, D., and Toren, M. (1994), "Cost and Efficiency in Nursing Homes: A Stochastic Frontier Approach", Journal of Health Economics, 13, pp. 281-300.

Wagstaff, A. (1989), "Estimating Efficiency in the Hospital Sector: A Comparison of Three Statistical Cost Frontier Models", Applied Economics, 21, pp. 659-672.

Zellner, A. (1989), "An Efficient Method for Estimating Seemingly Unrelated Regressions and Test for Aggregation Bias", Journal of the American Statistical Association, 57, pp. 585-612.

Zweifel, P. and Breyer, F. (1997), Health Economics, New York.

\section{SUMMARY}

This paper examines the cost efficiency in the nursing home industry, an issue of concern to Swiss policy makers because of the explosive growth of national expenditure on elderly care and the aging of the population. A stochastic cost frontier model has been applied to a panel of 1780 observations from 356 nursing homes operating over 1998-2002 in Switzerland. We compare the estimation results from different econometric techniques focusing on the specification of unobserved heterogeneity across firms. The potential effects of such unobserved factors on the estimation results and their interpretation have been discussed. The findings suggest that the economies of scale are an important potential source of cost reduction in a majority of Swiss nursing homes. Moreover the average performance of a representative nursing home is very close to the estimated best practice. 